\title{
Eduardo Roca Roca
}

Catedrático de Derecho Administrativo

\section{Administración Pública \\ y turismo}

SUMARIO: 1. EL FENÓMENO TURÍSTICO. 2. LOS ANTECEDENTES EN ESPAÑA. 3. TURISMO Y ADMINISTRACIÓN PÚBLICA. 4. SECTORES TURÍSTICOS. 5. EL “HOMBRE TURÍSTICO». 6. EL TURISMO SOSTENIBLE. LA NORMATIVA DE LA UNIÓN EUROPEA. 7. AMBIENTE Y TURISMO. 8. TURISMO Y OCIO: DEPORTE Y TURISMO. 9. LA EVOLUCIÓN DEL TURISMO SOSTENIBLE. 10. LOS ESTUDIOS SOBRE TURISMO SOSTENIBLE: MEDIDAS PARA CONSEGUIRLO. 11. EL TURISMO SOSTENIBLE EN ESPAÑA. 12. LA EXTENSIÓN MUNDIAL. 13. CONCLUSIÓN.

\section{EL FENÓMENO TURÍSTICO}

El Diccionario de la Real Academia de la Lengua Española recoge las palabras «viaje» y «turismo», en sentido distinto, de forma que la primera es la acción y efecto de viajar en el sentido de ir o desplazarse a cualquier lugar, siendo el viajero la persona que viaja o realiza el desplazamiento de una parte a otra utilizando diversos medios de transporte.

Frente a la larga tradición de la palabra «viaje» y «viajero», el citado Diccionario recoge recientemente la palabra «turista» y «turismo», que se recibe de las palabras inglesas tourism y tourist, para designar a la persona que recorre un país por distracción y recreo, así como la afición a viajar por placer, extendiéndose su significado a la organización de los medios conducentes a facilitar estos viajes.

Así pues, se encuentran estrechamente relacionadas las dos palabras si bien su contenido es distinto, pues mientras «viaje» es el desplazamiento de una parte a otra utilizando cualquier medio de transporte, y que implica multitud de finalidades, sin embargo, el turista es aquella 
persona que recorre un país, o viaja por placer con la única finalidad de su personal distracción y recreo.

Debe destacarse que la tendencia viajera de los seres humanos es consustancial con los mismos, si bien se vincula inicialmente primero con las guerras de conquista (Grecia, Imperio y República Romana, etc.), más tarde la extensión del Islam por el Norte de África llegando hasta más allá de los Pirineos. Descubrimiento y colonización de América. Colonización de Extremo Oriente, ingleses, franceses y portugueses, así como Norteamérica y Canadá y el Continente Africano.

Detrás de los ejércitos van los comerciantes y se inician los intercambios comerciales, económicos y personales. Recordemos que Colón pretendía llegar a las Indias Orientales, en busca de especias e igualmente los viajes de Marco Polo que tienen carácter fundamentalmente comercial.

Puede recordarse el viaje de Jerónimo Müncer por España a finales del siglo XV y las impresiones que describe en su Libro de Viajes, en especial la llegada a Granada el día 16 de octubre de 1494.

En el siglo XIX se producen los viajes de ingleses como los de Inglish, Ford, Washington Irving, Richard Borrow y los franceses Laborde, Barón de Davillier, Doré, etc., hasta el punto de que algunos realizan largas estancias en ciudades españolas, llegando a establecerse en ellas con carácter permanente.

La legislación española, desde los más remotos Fueros y Ordenanzas, continuando por la Legislación de Partidas y las Normas que se recogen más tarde en la Recopilación y en la Novísima Recopilación, se refieren a visitantes y la necesidad de que las fondas, posadas y casas de huéspedes, reúnan condiciones higiénicas aceptables.

Tanto los políticos como la literatura se preocupan de este fenómeno y encontramos referencias en la literatura clásica: En El Quijote: los lances en la Posada, el fantástico viaje de D. Quijote y Sancho en el Caballo Clavileño, y quienes hacen la broma y asisten al espectáculo.

En el año 1641 se produce la publicación de la obra de Luis Vélez de Guevara, El Diablo Cojuelo, y cuyo autor es recordado por Cervantes en su Viaje del Parnaso (título significativo) diciendo:

Este que es escogido entre millares de Guevara, Luis Vélez, es el bravo que se puede llamar quitapesares.

El Diablo Cojuelo (de Guevara) es un auténtico libro de viajes en el que Don Cleofás Leandro Pérez Zambullo, y el Diablo Cojuelo, realizan un esperpéntico viaje aéreo con el cual el Diablo premia a su libertador.

El viaje y el vuelo es un tema que también figura en los Libros Sagrados de la antigüedad, puede citarse el Libro de los Muertos, con viaje final a 
través de las aguas para llegar al descanso eterno y el juicio final, que encontraremos tanto en la religión coránica, en la civilización etrusca, los viajes de Ulises o de Orfeo en busca de Eurídice, o Alcestes que finalmente fue devuelto a la tierra, o la mítica aventura de Orfeo que proporciona tema a Virgilio, en las Geórgicas, y a Aristófanes, etc. Para llegar a la Divina Comedia, de Dante, en la que el poeta visita tanto el cielo como los infiernos en un viaje lleno de fantasía histórica mezclado con la mitología.

Pérez Galdós también utiliza la técnica de los viajes y en su obra «La Primera República» (Episodios Nacionales), lleva a Tito, protagonista de la Última Serie, en un viaje fantástico desde Madrid a Cartagena a lomos de un toro acompañado de Floriana sufriendo numerosas vicisitudes que recuerdan el viaje de Dante, pues desfilan en el viaje de Tito múltiples personajes fantásticos, mezcla de mitología e invención, llegando a afirmar Tito en un momento: «Soñé que estaba no en las Cortes, no en las calles de Madrid, sino en el Olimpo, habitual residencia de los dioses que fueron y que quizá lo eran todavía. La impresión que recibí fue la que produce un lugar visitado ya en tiempos muy remotos».

Cuando se recuerda este episodio literario creo que se pone de relieve la referencia a los derechos constitucionales de libertad de residencia y de circulación, que en muchos momentos históricos han estado limitados por razones políticas, sin embargo, El Diablo Cojuelo supone una ruptura total de las restricciones al ejercicio del derecho a la libertad de circulación y residencia, y por consiguiente una rotunda afirmación de estos derechos fundamentales, aunque el ejercicio de tales derechos se haya conseguido con la ayuda de un demonio menor. No podemos olvidar que el desplazamiento aéreo del Diablo Cojuelo desde Madrid a Sevilla tiene un complejo itinerario, ya que el Cojuelo pasa por Constantinopla, alborotando el serrallo del Gran Turco, así como un breve paso por Suiza y concretamente la referencia a la ciudad de Ginebra.

No es ahora el momento de insistir en los aspectos históricos y literarios de los viajes que se producen desde la más remota antigüedad, sino poner de manifiesto este hecho singular y que la Administración de los distintos países toman nota de esta realidad, a la vez que dictan normas de policía y fomento para regular las actividades relacionadas con los viajes así como con los espectáculos y atracciones en general, a cuyo efecto se puede citar la obra que Don Gaspar Melchor de Jovellanos publica en Gijón en 1790 bajo el título de Memoria para el arreglo de la Policía de los Espectáculos y de las diversiones públicas y sobre su origen en España, preocupándole que los españoles se divirtiesen mal y sobre todo que se diviertan poco «icómo es que la mayor parte de los pueblos de España no se divierten en manera alguna?».

Desde el punto de vista del control de los alimentos, subsistencias, sanidad pública e incluso de los enterramientos, aunque el tema no sea 
grato ni alegre, cabe citar a Tomás de Valeriola que publica en Valencia en 1798 su Tratado de la Policía.

Históricamente no existen movimientos organizados de desplazamientos masivos de población, y por lo tanto de turismo, pues sólo hay disposiciones aisladas.

La palabra turismo aparece por primera vez en España, en el R.D. de 6 de octubre de 1905 que creó la Comisión Nacional para el Fomento del Turismo, que se titulaba también para «Fomento de las excursiones artísticas y recreo del público extranjero»; el R.D. de 19 de julio de 1911 creó la Comisaría Regia de Turismo para el desarrollo y divulgación del mismo, constituyéndose la Junta Superior de Turismo como Órgano de apoyo. El desarrollo de la Normativa se inicia con la creación del Patronato Nacional de Turismo por R.D. 25 de abril de 1928, en el que se refunde la Comisaría Regia de Turismo funcionando junto a ella el Consejo General. Dotada con pocos medios se crea la Dirección General de Turismo que tiene escasa vida pues en 4 de diciembre de 1931 se vuelve a restaurar el Consejo General de Turismo.

Tras la Guerra Civil, la Ley 30 de enero de 1938 reorganiza la Administración Central y afecta al Ministerio del Interior el Servicio Nacional de Turismo, hasta que por Decreto-Ley de 19 de julio de 1951 se creó el Ministerio de Información y Turismo.

A partir de 1950, tras la conclusión de la Segunda Guerra Mundial, se produce una continuada recuperación económica mundial que dará lugar al incremento masivo del desplazamiento de viajeros generando turismo masivo, que tiene una especial significación para aquellos países que pueden ofrecer distracción o recreo, generando el llamado turismo de masas.

España es el tercer país receptor de turismo en el mundo después de Francia y Estados Unidos, si bien se sitúa en el segundo lugar en cuanto a los ingresos netos por turismo. En este sentido, se observa en las estadísticas oficiales que se venían computando globalmente los visitantes y los turistas, debiendo desglosarse a partir de 1996 en que se produce la entrada de 61,9 millones de visitantes de los cuales tienen el carácter de turistas 41,4 millones. En 1997 la cifra llega a 43 millones. La cifra ya fue muy elocuente pues la población española se situaba en 1997 en 40 millones de habitantes, lo cual quiere decir que nos había visitado una cantidad de personas superior en número a la población española, y que los 50 millones de turistas que visitaron España en 1999 superó con creces la cifra de población de España, mientras se calcula para el año 2000 que los turistas lleguen a los 55 millones.

Junto a esta indicación es necesario realizar una reflexión socioeconómica sobre la realidad española, y es la repercusión que dicho fenómeno produce sobre nuestra economía de forma que el $11 \%$ de la 
población activa española está trabajando en actividades relacionadas con el turismo ( 800 mil puestos de trabajo directo y 540 mil en forma indirecta de acuerdo con los datos proporcionados por la Asociación Madrileña de Empresas Organizadoras y Profesionales de Congresos).

Desde el punto de vista económico, los ingresos netos por turismo se cifraron en el año 1990 en 1,87 billones de pesetas; produciéndose un incremento gradual llegando en 1995 a 3,12 billones de pesetas; en 1996 a 3,46 billones de pesetas, para 1997 un ingreso neto de 3,6 billones de pesetas, en 1999, 50 millones de turistas y un ingreso de 5 billones de pesetas, lo que supone cerca del 10\% del P.I.B., y para el año 2000 se calcula un ingreso de 5,5 billones de pesetas.

El resumen es tremendamente expresivo para 1997: 43 millones de turistas generaron un ingreso neto de 3,6 billones de pesetas; en 1998, 44 millones de turistas han generado un ingreso de 4,5 billones de pesetas que en 2000 llegará a 5.5 billones de pesetas. Cerca de un millón quinientos mil españoles trabajan en el sector que constituye una de las primeras fuentes de ingresos para la configuración del P.I.B..

\section{LOS ANTECEDENTES EN ESPAÑA}

En España se inicia el turismo hace casi medio siglo como turismo de distracción y recreo, y comienza a concentrarse en el archipiélago de las Islas Canarias, primero, y seguidamente en las Islas Baleares, para residenciarse, a continuación, a lo largo de toda la costa mediterránea desde la Costa Catalana hasta las costas mediterráneas y las de Cádiz, generando paulatinamente importantes problemas de masificación humana que van desde el desplazamiento al alojamiento.

El desplazamiento afectará a toda clase de infraestructuras que integran los distintos medios de transporte, y a toda clase de vías, terrestres, marítimas y aéreas, si bien la especial configuración insular del archipiélago canario reconduce la entrada turística casi exclusivamente por vía aérea. Por consiguiente, el primer problema que plantea el turismo es la necesidad de contar con las necesarias e indispensables infraestructuras de transporte que puedan absorber la demanda millonaria. El segundo de los grandes problemas mencionados es el de los alojamientos, ya que es necesario contar con las correspondientes infraestructuras hoteleras para atender un número tan elevado de turistas.

\section{TURISMO Y ADMINISTRACIÓN PÚBLICA}

Pero el turismo no proporciona sólo beneficios y cifras favorables, sino que plantea graves e importantes problemas para la Administra- 
ción Pública, que han dado lugar a la necesidad de que se configure una Administración Pública especializada bajo la denominación de "Administración Turística», que se produzca una regulación jurídica que se integra como sector particular dentro del Derecho administrativo español, como «Derecho administrativo turístico»y, en algunas ocasiones sólo como «Derecho turístico", ya que la regulación del fenómeno alcanza a sectores que se sitúan fuera del tradicional ámbito del Derecho administrativo, como son las facetas objeto de regulación por el Derecho mercantil, el Derecho civil o el Derecho laboral, entre otros.

Así pues, puede afirmarse que el Derecho turístico se comienza a configurar como una rama del Derecho administrativo que se encuentra en fase de sustantivización, a la vez que contacta y se relaciona con otras ramas del Derecho.

Desde el punto de vista material, es sobradamente conocido el efecto multiplicador del turismo, consecuencia directa de su incidencia plurisectorial, lo que genera una estructura transversal de su normativa que afecta a la multiplicidad y variedad de sectores a los que antes se ha hecho mención, pues, insistimos, que en el momento actual es la mayor industria mundial por delante del automóvil, el acero, la electrónica y la agricultura, calculándose que proporciona empleo a ciento veintisiete millones de personas en el mundo, lo que supone que el turismo proporciona empleo directo al $6,5 \%$ de la población trabajadora.

\section{SECTORES TURÍSTICOS}

De forma sumaria destaquemos que el turismo incide en los siguientes ámbitos:

- Alojamientos en general.

- Infraestructura de toda clase de transportes: terrestres, aéreos y marítimos.

- Costas, y, concretamente, playas, puertos en general y puertos turísticos.

- Espacio aéreo, aeropuertos.

- Patrimonio Histórico Artístico.

- Contemplación y visita de la naturaleza.

El carácter plurisectorial del turismo no se agota con los aspectos enunciados ya que incide sobre otra serie de ellos estrechamente relacionados con los servicios, pero podemos resumir esta pluralidad en las siguientes vías o líneas de actuación:

A) Planificación del territorio. 
B) Tutela del medio ambiente, y de aquí el crecimiento sostenible y en especial el concepto de turismo sostenible.

C) El turismo no es un concepto único en el momento actual sino que se ha producido una diversificación o pluralidad de tipologías: turismo estacional o turismo permanente; turismo estable en cuanto tiene por finalidad el descanso del turista y que fundamentalmente se concentra en las zonas costeras; turismo deportivo, cultural, de naturaleza, de valoración de la flora y de la fauna, costumbrista, religioso, de riesgo, turismo ecológico. Incluso se puede hablar de un turismo científico o de un turismo profesional en que se compatibiliza la actividad científica, industrial, profesional, etc., con una finalidad exclusivamente turística.

Lo anteriormente expuesto podemos sintetizarlo en los siguientes sectores que suponen las correspondientes actuaciones de las Administraciones Públicas:

En primer lugar, la planificación del territorio, donde habrán de valorarse todos los aspectos relacionados con los sectores a que antes se ha hecho mención, desde los alojamientos a las infraestructuras relacionadas con los transportes.

En segundo lugar, el turismo incide sobre el medio ambiente y se encuentra en estrecha relación con el planeamiento y la ordenación del territorio.

En tercer lugar, se nos presenta el gran problema del turismo sostenible, y hasta dónde se puede planificar y utilizar los distintos elementos que integran el ambiente y la necesidad de limitar el crecimiento turístico a fin de que no se produzca deterioro del medio ambiente.

\section{EL «HOMBRE TURÍSTICO»}

A titulo de mera curiosidad tengase en cuenta que «el hombre turístico» puede transformarse, de forma consciente o inconsciente, en «hombre depredador» del ambiente, en el más amplio sentido de la palabra, y del Patrimonio Cultural.

En este sentido recordemos la necesidad de cerrar varias tumbas en el Valle de las Reinas y en el Valle de los Reyes, cuyas pinturas se han degradado por la alteración del microclima al modificarse el grado de humedad de las tumbas, sin olvidar las pérdidas producidas de forma premeditada por el robo de algunos «hombres depredadores». Sólo el roce del calzado de los visitantes acaba deteriorando el suelo de los monumentos.

En el sentido expuesto se puede citar el cierre a la visita pública de las Cuevas de Altamira conocidas como la «Capilla sixtina» del arte rupestre en España. 
Las alteraciones climáticas producidas en los más importantes museos del mundo, como consecuencia de las alteraciones que genera la visita masiva de los visitantes, ha exigido sistemas de climatización para regular temperatura y humedad, así como la serie de microorganismos, hongos, bacterias, etc., que pueden alterar las condiciones de los citados museos, que reciben millones de visitantes, o simplemente los conjuntos monumentales seriamente amenazados por la visita multitudinaria como es el caso del Conjunto Monumental de La Alhambra y el Generalife que es visitado por cerca de dos millones de turistas cada año, de forma que el roce del calzado en los pavimentos, el de los vestidos en columnas, alicatados y yeserías, o la alteración de temperatura y de la humedad producen sensibles alteraciones.

A titulo ilustrativo se pueden traer a colación dos ejemplos de vandalismo producidos no hace mucho tiempo en Roma: La necesidad de restaurar la Escalinata de la Trinità dei Monti, obra del siglo XVIII que se encontraba en un avanzado estado de degradación a causa de la contaminación y del vandalismo de los visitantes, hasta el punto de que el Ayuntamiento de Roma aprobó una normativa según la cual «la escalinata podrá ser utilizada exclusivamente por el público para tránsito peatonal y no para concentración en sus gradas...y... prohíbe consumir alimentos, bebidas, arrojar desperdicios y escribir en su superficie y muros... y nadie se podrá detener entre la medianoche y la madrugada, para permitir que se efectúen las tareas de limpieza»; la Ordenanza autoriza que el público pueda sentarse accidentalmente, pero prohíbe terminantemente cocinar en la escalinata, como se hacia hasta hace poco tiempo, y se impondrán multas de importancia para los transgresores. Recordemos el deterioro producido por tres personas que se bañaban en Roma en la Fuente de los Ríos, en la Plaza Navona, obra de Bernini, en la que fracturaron en tres pedazos la cola de mármol de un Dragón del Conjunto. Posteriormente se ha convertido el asalto a esta fuente en una forma de protesta de determinados grupos minoritarios.

Hace años que los grandes triunfos de un equipo de futbol de Madrid es celebrado por sus seguidores invadiendo la Fuente de Cibeles que viene şufriendo importantes daños materiales.

\section{EL TURISMO SOSTENIBLE. LA NORMATIVA DE LA UNIÓN EUROPEA}

Los fenómenos sociales son de difícil predicción, y aún más prever su posible regulación jurídica, por esta razón las relaciones sociales son las que demandan una regulación externa -la norma- que resuelva problemas y conflictos que se producen en dichas relaciones. 
Éste es el problema que se plantea con el turismo: es un hecho que produce una multiplicidad de efectos sociológicos, económicos, materiales, etc., cuya magnitud no pudo preverse con antelación, y por consiguiente no existían normas que pudieran regular tan complejos problemas. El ambiente debe contemplarse con una visión global, teniendo en cuenta el carácter pluridisciplinar de las ciencias que inciden en el mismo, tanto desde el punto de vista de su regulación como de su tratamiento y gestión material.

El Tratado de Roma de 25 de marzo de 1957, constitutivo de la CEE, no otorgó al turismo la categoría de Subsector económico e, incluso, no se hacía mención al tema pese a la importancia que ya empezaba a tener. Progresivamente la Comunidad adoptará una serie de decisiones que afectan al turismo, y entre ellas podemos destacar las siguientes:

- Las ayudas económicas que el Fondo Europeo de Desarrollo Regional (FEDER) presta para acondicionamiento de hoteles, aldeas de vacaciones, campings, etc., y, en especial, las ayudas a fondo perdido.

- Los préstamos a bajo interés que comienza a conceder el Banco Europeo de Inversiones con el fin de promover actividades turísticas.

Así pues, no existe una regulación sistemática de la $\mathrm{CEE}$ respecto del turismo, el cual viene afectado por regulaciones sectoriales y competencias marginales y transversales como son: la libre circulación de mercancías, política agraria, sistema monetario, unificación del IVA, libre circulación de capitales y de mano de obra, etc.

En el año 1981, se integró Grecia en la Comunidad, y en el año 1986 lo hicieron España y Portugal, por lo que se produjo una fuerte representación de países turísticos en la Comunidad que provocan en la misma el inmediato interés por el turismo. La Comisión del Parlamento Europeo aprobó en 1982 unas orientaciones sobre política comunitaria de turismo con el título «Por una política comunitaria del Turismo», que fue una declaración de buenas intenciones acogida con interés por todos los Estados Miembros, siendo declarado el año 1990 Año Europeo del Turismo para promover el turismo social, rural y cultural durante todo el Año.

El Acta Única Europea de 17 de febrero de 1996 no introduce grandes novedades en la materia siendo destacable que el Tratado de Maastricht de 7 de febrero de 1992 declaró en sus artículos 2, y 3.t), que, para conseguir entre los Países Miembros un desarrollo armonioso y equilibrado de las actividades económicas, un crecimiento sostenible y no inflacionista, que respetase el medio ambiente, un alto grado de convergencia 
de los resultados económicos, un alto nivel de empleo y de protección social, la elevación del nivel y de la calidad de vida, la cohesión económica y social, y la solidaridad entre todos los Estados, sería preciso adoptar medidas, entre otros, en los ámbitos de la energía de la protección civil y del turismo.

Así pues, se inicia con cierto retraso el interés de la CEE (Unión Europea desde 1992) por el turismo, pues el citado Tratado de Maastricht de 1992 preveía una Conferencia de representantes de los Gobiernos de los Estados Miembros para los años 1996-97, pero hasta la fecha no se ha iniciado dicha Conferencia Intergubernamental y sólo se producen recomendaciones, dictámenes y resoluciones del Consejo no vinculantes, aunque no se puede olvidar que en 1989 la Comisión acordó que la Dirección General 23a se ocupase de la política de empresas, comercio, turismo y economía social. En el Parlamento Europeo, la $10^{\mathrm{a}}$ Comisión Permanente (Comisión de Transportes y Turismo) es la que tiene atribuida competencia turística.

En síntesis, la UE no tiene un cuerpo normativo sistemático respecto del turismo, si bien regula una serie de materias conexas con el mismo como son: medio ambiente y ecología, agencias de viaje, seguridad e información normalizada en hoteles, prácticas abusivas y competencia desleal y, en general, política comunitaria del turismo.

La Comisión de la UE aprobó en abril de 1996 un Programa plurianual de Desarrollo Turístico, bajo la denominación de PHILOXENIA, que se inició el día 1 de enero de 1997 con una duración de cuatro años y que terminó el 31 de diciembre del año 2000.

Los objetivos básicos de dicho Programa eran los siguientes:

1. Mejorar el conocimiento del sector turístico Europeo desarrollando la oportuna información, centralizando la correspondiente a los distintos países que lo integran y el estudio de los variados sectores comunitarios que afectan al turismo.

2. Mejorar el nivel legislativo y financiero del turismo estrechando la cooperación con los Estados Miembros, y en especial con el sector de la economía o cualquier otro interesado.

3. Mejorar la calidad del turismo europeo promocionando el turismo estable y suprimiendo los obstáculos que puedan dificultarlo.

4. Incrementar la afluencia de turistas procedentes de países ajenos a la UE, promocionando a los Estados Miembros como destino turístico.

5. Fomentar el crecimiento económico y la creación de empleo en los países de la Unión en el sector turístico.

Para la consecución de estos objetivos preveía que las distintas Instituciones de la UE intensificaran su cooperación con todas las Autoridades Nacionales y, en especial, con las Administraciones Regionales y Locales de los Estados Miembros. Esta declaración es de gran importancia ya que reconoce la existencia del turismo sostenible, la estabiliza- 
ción y estacionalización del mismo y la intervención que en este sector tienen tanto los Estados Nacionales como las Administraciones Regionales y Locales de los Estados que integran la UE

\section{AMBIENTE Y TURISMO}

El ambiente es único, pero está integrado por una serie de sectores que se relacionan entre sí de forma transversal y, de esta manera, se produce una estrecha relación entre industria, energía, transporte, agricultura y turismo, pues el turismo no puede existir sin los medios que generan los otros sectores, que, a su vez, están potenciados por la masiva demanda turística, y los efectos que todo ello produce en el ambiente.

Las actuaciones legislativas en materia de turismo han sido dispersas en España, ya que no ha existido una visión de conjunto del problema e igualmente se puede decir de la Unión Europea, integrada por una diversidad de países de una alta recepción turística (España, Italia, Francia, Grecia), mientras que la llegada de turismo a los restantes países tiene una menor importancia.

Así pues, la UE se planteó, muy limitadamente, como antes se ha indicado, la regulación de los problemas que genera el turismo, y sólo lo ha hecho de forma parcial, en relación con problemas específicos y sin realizar un estudio de conjunto de este importante sector. En este sentido, el Consejo elaboró una Propuesta de Directiva (SOCE n ${ }^{\circ} 129$, de 25-4-97) sobre la evaluación ambiental de determinados planes y proyectos públicos, y en ella se deben destacar los siguientes aspectos:

A partir del año 2000, las Administraciones públicas deberán realizar una evaluación medioambiental de los planes y programas que prevean iniciar en los sectores del transporte (incluidos los corredores de transporte, las instalaciones portuarias y los aeropuertos), la energía, la gestión de residuos, la gestión de recursos hídricos, la industria (incluida la extracción de recursos minerales), las telecomunicaciones y el turismo. Esta evaluación deberá incluir el análisis de la naturaleza, las dimensiones, la localización y las condiciones de explotación de dichos proyectos.

Los proyectos deberán consistir en la realización de trabajos de construcción u otras intervenciones en el medio rural o el paisaje, incluidas las destinadas a la explotación de los recursos del suelo.

La declaración medioambiental deberá contener información suficiente para evaluar las repercusiones significativas, directas e indirectas, de la ejecución del Plan o Programa sobre los seres humanos, la fauna, la flora, el suelo, las aguas, la atmósfera, el clima, el paisaje, los bienes materiales y el patrimonio cultural. 
De esta forma, el turismo es integrado por la Unión Europea en el Ambiente, junto a los sectores y elementos que se consideraban su base esencial (agua, suelo, fauna y flora), que van ampliándose, destacando la especial relación del Ambiente con el Turismo y con el Patrimonio Cultural (concepto que es utilizado en sentido amplio), y de esta forma -y como antes se decía- apreciamos el carácter transversal del turismo en relación con el ambiente, y de forma especial con el Patrimonio Cultural, de cuya forma llegamos al planteamiento, no sólo de un «desarrollo sostenible», en general, sino de un «turismo sostenible» en especial.

\section{TURISMO Y OCIO: DEPORTE Y TURISMO}

Dentro de la especialización turística antes mencionada, el ocio y la realización de actividades deportivas realizadas a su amparo constituyen un sector de gran trascendencia sociológica y económica, ya se trate de la asistencia turística a grandes acontecimientos deportivos o bien el desplazamiento turístico para participar de forma activa en actividades de naturaleza deportiva.

A título de ejemplo, entre las distintas actividades deportivas, destaca especialmente el deporte del golf, que está adquiriendo una extraordinaria relevancia en los últimos años, perdiendo su inicial carácter elitista.

En estas líneas solamente constatamos la existencia de una actividad turística y deportiva como es la práctica deportiva del golf, sin necesidad de hacer referencia a sus antecedentes históricos, pues nos encontramos con un fenómeno deportivo perfectamente consolidado en la actualidad, respecto del que España se va a configurar como uno de los primeros países receptores de Europa por evidentes razones climáticas, geográficas, etc.., lo que genera una calidad turística específica $y$, en consecuencia, un valor económico con directa influencia sobre nuestra economía, aunque el golf no se haya reconocido aún como deporte olímpico, si bien tiene un amplio abanico de usuarios en los que caben distintas edades y condiciones físicas y económicas.

\section{LA EVOLUCIÓN DEL TURISMO SOSTENIBLE}

La Primera Conferencia de las Naciones Unidas sobre el Medio Ambiente Ambiente, celebrada en Estocolmo en 1972, es el inicio de una nueva forma de contemplar los problemas ambientales reconociendo al ambiente su carácter transversal, siendo destacable que:

- En el mismo año 1972 se inició la crisis de la energía. 
- se hace público el primer informe del Club de Roma sobre límites del crecimiento y se celebra en Estocolmo la primera Conferencia sobre el Medio Humano, y

- se firmó el Convenio de París sobre el Patrimonio Mundial, Cultural y Natural bajo los auspicios de la UNESCO.

El concepto de «sostenible» aparece por primera vez en el informe de las Naciones Unidas de 1987 sobre «Nuestro Futuro Común».

Es importante destacar en el Convenio de París de 1972 la protección y conservación de la naturaleza y de los lugares culturales como conceptos complementarios, de tal forma que la identidad cultural se integra en el medio natural en el que se produce.

Son destacables: la Conferencia de Naciones Unidas sobre polución, en 1974, el especial interés que tienen los planes sobre el Mediterráneo de 1975 y de 1976, respectivamente, conocidos por «Plan de Acción del Mediterráneo» y «Convenio de Barcelona para la Protección del Mediterráneo».

La Conferencia de Río de Janeiro de 1992 (Conferencia de Naciones Unidas sobre el Medio Ambiente y el Desarrollo o «Cumbre de la Tierra») que institucionaliza el concepto de "crecimiento sostenible» y de «sostenibilidad» teniendo una especial importancia la Agenda 21 que compromete a los Países firmantes al desarrollo de políticas adecuadas para conseguir un desarrollo sostenible.

Curiosamente unos días después de la Conferencia de Río, la Comisión Europea aprobó, con fecha 21 de junio, el V Programa Comunitario de Política y Actuación en materia de Medio Ambiente y desarrollo sostenible con el título "Hacia un Desarrollo sostenible ", en el que se mantiene la necesidad de integrar el medio ambiente en todas las políticas sectoriales de la UE. y de sus Estados Miembros, a cuyo efecto este V Programa selecciona cinco sectores básicos a los que se deben de aplicar técnicas de desarrollo sostenible y que son:

- Industria

- Energía

- Transporte

- Agricultura

- Turismo

A dichos efectos deberá centrar el Programa su actuación sobre siete temas fundamentales:

1. Cambio climático

2. Acidificación y calidad de la atmósfera

3. Protección de la naturaleza y biodiversidad 
4. Gestión de los recursos hídricos

5. El medio ambiente urbano

6. Zonas costeras

7. Gestión de residuos

En 1995 la UE elaboró el informe de Medio Ambiente de la Unión como base para revisar el V Programa hasta el año 2000, y en el mismo año se produce el informe sobre "Ciudades europeas sostenibles», debiendo destacarse también la «Cumbre de las ciudades, Hábitat II», que recoge los resultados de la Conferencia sobre asentamientos humanos celebrada en Estambul en junio de 1996.

En octubre de 1996 se celebró en Lisboa la II Conferencia Europea sobre Ciudades Sostenibles y en 1997 se conmemora el V Aniversario de la Cumbre de Río de Janeiro en Sesión especial de la Asamblea General de las Naciones Unidas.

\section{LOS ESTUDIOS SOBRE TURISMO SOSTENIBLE: MEDIDAS PARA CONSEGUIRLO}

En el ámbito del turismo ha tenido una directa influencia el concepto de sostenibilidad como consecuencia de la cualificación de este sector y su relación con el ambiente, siendo en el año 1991 cuando se producen los primeros estudios destacables sobre turismo sostenible en el Congreso de la Asociación Internacional de Expertos Científicos del Turismo, destacando la complejidad del problema, como en su momento hemos puesto de relieve como consecuencia del turismo de masas, frente a los intereses de la Comunidad sobre la que presiona el turismo, por cuya razón se concibe el turismo sostenible «como un turismo que mantiene un equilibrio entre los intereses sociales, económi$\cos$ y ecológicos», de tal forma que debe de compatibilizar las actividades recreativas y económicas con la conservación de los valores naturales y culturales.

A partir de la cumbre de Río de 1992 se inician una diversidad de estudios sobre el turismo sostenible, y como ya se ha indicado se recoge por la UE en 1992 en el V Programa Comunitario de Política y Acción en materia de Medio Ambiente y Desarrollo sostenible, declarando que el turismo es «un ejemplo claro de la estrecha relación existente entre el desarrollo económico y el medio ambiente, con toda su secuela de beneficios, tensiones y posibles conflictos», si bien este impacto se pondera de diversa forma según el tipo de turismo, conducta de los turistas, calidad de los servicios turísticos, etc., destacando que la tensión turística de mayor intensidad se pro- 
duce sobre las costas y posteriormente sobre la montaña, lo cual obliga a plantear una serie de normas de conducta para coordinar las relaciones entre turismo y medio ambiente, que se centran fundamentalmente en la planificación territorial (uso del suelo, normas de construcción, lucha contra las edificaciones ilegales), tráfico y seguridad vial, infraestructuras y, en especial, las relacionadas con los medios de transporte, saneamiento, contaminación acústica, preservación de zonas naturales, etc.

El citado Programa de Acción previó un conjunto de medidas relacionadas con el turismo ( Plan de medidas comunitarias en favor del turismo") para conseguir un desarrollo coordinado y sostenible de turismo y ambiente, a cuyo efecto se contienen las siguientes medidas:

- Inventario de recursos turísticos de los Estados Miembros.

- Conseguir un reparto a lo largo del año de las estancias turísticas y de las concentraciones estacionales.

- Guías prácticas para la industria turística y proyectos piloto sobre turismo ecológico.

- Código de conducta para el turista.

- Intercambios de información y experiencia.

- Medidas de fomento turístico-ambientales a través de premios, recompensas, etc.

$-$

La Comisión resume los objetivos del Programa en las siguientes ideas:

1. Delimitar los tipos de turismo y las acciones que proceden en cada uno de ellos.

2. Un adecuado comportamiento de los turistas en relación con el principio de sostenibilidad.

3. Calidad de los servicios turísticos para la conservación del medio ambiente.

En desarrollo de la Agenda 21 de la Cumbre de Río, se celebró en 1993 en Francia la I Conferencia Euromeditarránea sobre Turismo y Desarrollo Sostenible, y la Organización Mundial del Turismo, en 1993, elabora un documento sobre el «Turismo hacia el año 2000» en que declaraba: «El desarrollo turístico sostenible responde a las necesidades de los turistas actuales y las regiones receptoras, protegiendo y mejorando las oportunidades del futuro. Se representa como regulador de todos los recursos, de manera que las necesidades económicas, sociales y estéticas puedan ser satisfechas manteniendo la integridad cultural, los procesos ecológicos esenciales, la diversidad biológica y los sistemas en defensa de la vida». 
Para conseguir el desarrollo sostenible del turismo y su integración con el medio ambiente se establecen una serie de aspectos que van desde la recogida y tratamiento de residuos, al abastecimiento de agua, transportes, planificación del territorio, etc. En 1994 vuelve otra vez a ocuparse la Organización Mundial del Turismo haciendo público un documento sobre el «Desarrollo turístico sostenible. Guía para planificadores locales».

En el año 1995, se celebró en Lanzarote (España) la I Conferencia Mundial para el Turismo Sostenible, auspiciada por importantes organismos supranacionales: Naciones Unidas, Organización Mundial del Turismo, Unión Europea y la Administración Española, así como la Regional y Local de Canarias. Dicha Conferencia dio lugar a la «Carta del Turismo sostenible» donde se contempla la estrecha relación entre sostenibilidad, desarrollo y conservación de los recursos y el papel fundamental del turismo como principio de sostenibilidad en las Administraciones Locales, en relación con las cuales se produce un pronunciamiento èspecial en su Tercera Declaración al referirse al «reconocimiento de las tradiciones de las Comunidades Locales, y el apoyo de su identidad, cultura e intereses que deben ser referentes obligados", resaltando la importancia que tiene la participación de las Administraciones Locales en cualquier tipo de estructuración de planes de desarrollo turístico sostenible, como declara el Principio $4^{\circ}$ de la citada Conferencia al establecer que el desarrollo turístico sostenible presupone necesariamente la solidaridad, el respeto mutuo y la participación de todos los actores implicados en el proceso, tanto públicos como privados. Esta concertación ha de basarse en mecanismos eficaces de cooperación a todos los niveles: Local, Nacional, Regional e Internacional, así como la necesidad de relacionar el turismo sostenible con los otros sectores relacionados con el ambiente, tales como agricultura, industria o transporte, pues la sostenibilidad no puede conseguirse si alguno de estos sectores no lo son.

La citada "Carta del Turismo Sostenible», aprobada en Lanzarote el 27-28 de abril de 1995, tiene una gran importancia ya que es el primer documento que estableció con carácter mundial los siguientes aspectos:

La extensión del turismo, su carácter transversal, la fragilidad de los recursos afectados ante la necesidad de mantener la calidad ambiental, reconoce que el turismo es un medio para promover el acercamiento y la paz entre los pueblos y la necesidad de que se produzcan las necesarias alianzas entre los responsables de la actividad turística a fin de mantener el equilibrio del ambiente, el patrimonio cultural y el desarrollo sostenible.

La Agencia Europea del Medio Ambiente, en 1995 realizó un detallado informe sobre el ambiente en Europa dedicando un capítulo al turismo desde el punto de vista sostenible y la necesidad de realizar estudios de impacto ambiental en aquellas zonas en que se produzca ac- 
tividad turística, tales como Parques nacionales, áreas protegidas, zonas rurales, sectores de montaña, costas, ciudades y lugares históricos, así como parques temáticos y de ocio.

Hay que hacer una especial insistencia en la necesidad de coordinar a las distintas Administraciones que intervienen en el proceso Turismo-Ambiente, para que no se produzcan actuaciones divergentes y contradictorias, de tal forma que no sólo hay que planificar, sino que también hay que poner un especial cuidado en coordinar la materialización de los Planes de actuación en el ámbito del Turismo y del Ambiente.

\section{EL TURISMO SOSTENIBLE EN ESPAÑA}

Se debe hacer referencia a la recepción de estas ideas en España pues la Administración Turística del Estado aprobó el primer Plan marco de competitividad del turismo español en 1992, renovado a su vencimiento, teniendo en cuenta la importancia que tiene la relación entre turismo sostenible, competitividad, desarrollo equilibrado y respeto del ambiente y recursos naturales así como los aspectos culturales.

En el año 1997 se continúa consolidando la idea de turismo sostenible en relación con el ambiente y el crecimiento sostenible, a cuyo efecto se han venido celebrando una serie de reuniones como ha sido el Seminario sobre Evaluación de la capacidad de carga para el turismo en las áreas costeras del Mediterráneo, dentro del Plan de acción del Mediterráneo, y la Administración española ha hecho público su «Plan de estrategias y actuaciones de la Administración General del Estado en materia turística», que destaca la importancia de definir un nuevo modelo de desarrollo turístico desde el punto de vista sostenible, que va desde la consolidación de los destinos estables y estacionales del turismo español a la mejora de la competitividad mediante un turismo de calidad y la conservación del ambiente.

En España se viene haciendo una importante experiencia de «desestacionalizar» el Turismo, y contribuir a su sostenibilidad en «temporada baja», a cuyo efecto las distintas Administraciones han llegado a acuerdos con los representantes de la industria hotelera que ofrece estancias para las personas de la Tercera Edad (jubilados, etc.), calculados al precio necesario para cubrir los costos de funcionamiento, de cuya forma se mantienen en adecuado uso las infraestructuras hoteleras y se conservan los puestos de trabajo en su casi totalidad. 


\section{LA EXTENSIÓN MUNDIAL}

El problema de la realización de un turismo sostenible no se limita exclusivamente al mundo occidental, sino que tiene carácter mundial, pues el turismo ha adquirido carácter planetario y afecta desde los grandes continentes a las pequeñas islas que se masifican por un turismo imprevisible. En este sentido, los países asiáticos y del Pacífico celebraron en 1999, en las Islas Maldivas, una «Reunión Ministerial de Asia y el Pacífico sobre turismo y medio ambiente», bajo los auspicios de la Organización Mundial del Turismo, dando lugar a la correspondiente petición de que se produzca un uso sostenible de los recursos y una planificación integrada del turismo para la sostenibilidad.

También durante 1999 se produjo la Declaración de Berlín sobre Diversidad Biológica y Turismo Sostenible que ha tenido como objetivo básico la adecuación de los principios de diversidad biológica contenidos en la Cumbre de Río de 1992 y su aplicación al sector turístico, de tal forma que el turismo garantice la conservación de la biodiversidad y del medio ambiente natural.

\section{CONCLUSIÓN}

Todos los países van adquiriendo conciencia de su responsabilidad en materia de turismo y de su sostenibilidad, aunque no existe una legislación específica y sistemática del sector. En el caso de España se han producido una serie de disposiciones diversas desde la década de 1950, si bien el panorama se complica a partir de 1978 en que la Constitución española prevé el reparto de competencias entre Estado y Comunidades Autónomas, las cuales asumen la promoción y ordenación del turismo, si bien el Estado conserva una serie de competencias hacia el exterior, así como un conjunto de competencias que transversalmente inciden sobre el turismo, como es el supuesto de costas, puertos, grandes infraestructuras del transporte, etc. Ahora bien, las competencias que asumen las Comunidades Autónomas españolas no se producen con carácter exclusivo, pues junto al ámbito competencial del Estado coexisten las competencias sobre turismo de las entidades locales y de forma especial de los Ayuntamientos cuya legislación específica (Ley de Bases de Régimen local, 7/1985, y su legislación de desarrollo) reconocen competencia a estas entidades locales en materia de turismo, como ya se reconoce también en los documentos internacionales o de la Unión Europea a que hemos venido haciendo mención.

En síntesis, el fenómeno turístico tiene una importancia excepcional, como se indicaba al principio, y ha de ser estudiado de forma para- 
lela con el ambiente, pues no pueden conseguirse los ideales previstos en los grandes convenios y declaraciones internacionales sobre desarrollo sostenible, si el turismo no tiene el mismo carácter sostenible, de aquí la necesidad de un estudio sistemático y metodológico de este sector socioeconómico y la necesidad de que se establezcan un conjunto de principios y de regulaciones normativas que sean aceptados y reconocidos internacionalmente, tanto por las Organizaciones y estructuras supranacionales, como por los distintos Estados, así como por las distintas estructuras organizativas de los mismos: Regiones, Administraciones Locales, etc. 
DA-2001, núms. 259-260. EDUARDO ROCA ROCA. Administración Pública y turismo

DA-2001, núms. 259-260. EDUARDO ROCA ROCA. Administración Pública y turismo 